\title{
Defining optimal body iron
}

\author{
James D. Cook \\ Department of Medicine, University of Kansas Medical Center, 3901 Rainbow Boulevard, Kansas City, Kansas 66160, USA
}

\begin{abstract}
The major liabilities of Fe lack include defects in psychomotor development in infants, impaired educational performance in schoolchildren, increased perinatal morbidity, and impaired work capacity. Few if any of the relevant investigations have demonstrated these abnormalities in the absence of anaemia. Consequently, adequate Fe nutrition can be defined as a normal haemoglobin concentration. On the other hand, optimal Fe nutrition should be regarded as sufficient body Fe to avoid any limitation in tissue Fe supply, termed Fe-deficient erythropoiesis. A variety of laboratory measurements have been used to identify this milder form of Fe deficiency, including serum ferritin, transferrin saturation, erythrocyte protoporphyrin, mean corpuscular volume, and more recently the concentration of the soluble fragment of transferrin receptor in serum. Recent studies indicate that the serum transferrin receptor is the preferred measurement, because enhanced synthesis of the transferrin receptor represent the initial cellular response to a declining Fe supply. Moreover, unlike other methods, it is not affected by chronic inflammation or infection which are often confused with Fe deficiency. In an otherwise normal healthy population the transferrin receptor : ferritin value provides a useful quantitative index of body Fe over a wide spectrum of $\mathrm{Fe}$ status, ranging from Fe repletion to Fe-deficiency anaemia. It is concluded that optimal Fe nutrition is best defined as a normal haemoglobin, serum ferritin and transferrin receptor concentration.
\end{abstract}

\section{Iron deficiency: Serum transferrin receptor}

A definition of optimal body Fe should take into account the functional consequences of Fe deficiency and the severity of the deficiency that produces them. Awareness of the critical importance of $\mathrm{Fe}$ in $\mathrm{O}_{2}$ transport and storage has fostered the development of a large array of laboratory methods to assess the size of various body Fe compartments. Proper application of these techniques can provide a highly accurate and quantitative measure of body Fe status. It has become common practice in recent years to define two levels of the severity of $\mathrm{Fe}$ deficiency depending on the presence or absence of anaemia. More advanced deficiency is accompanied by a reduction in the packed cell volume or haemoglobin concentration, and thus referred to as Fe-deficiency anaemia (IDA). Laboratory evidence of milder Fe deficiency without anaemia will be referred to as Fe deficiency (ID) in the present review. The laboratory definitions of IDA and ID will be discussed in more detail (see pp. 491-492). In decreasing order of importance and/or strength of supporting evidence, the functional consequences of Fe lack include defects in psychomotor development in infants, impaired educational performance in schoolchildren, increased perinatal morbidity in pregnancy, and impaired work capacity in adults.

\section{Liabilities associated with iron deficiency \\ Defective psychomotor development in infants}

There is considerable evidence that deficiency of Fe which occurs during the first 2 years of life can significantly impair mental and motor development (De Andraca et al. 1997). Two large epidemiological studies form the core of our knowledge on the subject. In a study conducted in Costa Rica in infants during their second year of life, infants with IDA scored significantly lower in tests of both motor and mental development as compared with those without anaemia (Lozoff et al. 1987). These results were similar to the findings reported in a Chilean case-controlled study in which a cohort of healthy 3-month-old infants were randomized to receive or not receive fortified milk and cereal until 12 months of age (Walter et al. 1989). When evaluated at 1 year of age, those infants with IDA had lower 
scores on both mental and motor developmental tests as compared with non-anaemic infants. In both these studies, the scores on mental and motor tests in the infants with IDA fell within the normal range, and in neither trial did 10 weeks of intensive Fe replacement improve verbal or motor performance.

Subsequent reports have been generally consistent with these early trials. In a double-blind study in 12-18-monthold Indonesian infants randomized to receive 4 months of $\mathrm{Fe}$ or placebo therapy, significant differences in mental and motor development scores were observed between those infants with IDA and the non-anaemic infants $(P<0.01$; Idjradinata \& Pollitt, 1993). However, the results differed from the earlier reports in that 4 months of Fe therapy resulted in a significant improvement in the IDA group $(P<0.001)$ relative to those infants with better Fe status, indicating a degree of reversibility of the abnormality. In a more recent study designed to examine the question of reversibility in greater detail, developmental tests and haematological studies were performed in thirty-two infants with IDA and fifty-four non-anaemic control infants between 12 and 23 months of age before and after giving oral $\mathrm{Fe}$ for 6 months (Lozoff et al. 1996). Significantly lower mental scores were observed between those infants with IDA and the non-anaemic participants at baseline, but the difference persisted despite extended Fe therapy. This resistance of the reduced mental performance to prolonged Fe therapy led the authors to conclude that IDA may serve as a marker for a variety of factors affecting infant development adversely. Indeed, there is a growing impression among authorities in this field that IDA may represent only one aspect of a wide spectrum of nutritional, social or economic factors which act in concert to impair full development during the first 2 years of life.

\section{Impaired education performance in schoolchildren}

Investigation on the related question of whether $\mathrm{Fe}$ deficiency is associated with impaired scholastic performance or learning ability beyond infancy was pioneered by Pollitt, who recently summarized his experience (Pollitt, 1997). The first investigation was performed in central Java where hookworm infection contributed to a high prevalence of IDA (Soemantri et al. 1985; Chwang et al. 1988). Three separate psychological tests were administered to seventyeight children with IDA and forty-one non-anaemic children with a composite mean age of 11 years; a marked difference between anaemic and non-anaemic children was observed at baseline in one of the three tests. In a later study designed to replicate the Indonesian study, 1775 children aged 9-12 years from Thailand were enrolled in a study that after haematological evaluation yielded 101 with IDA, fortyseven with ID and 1210 who were Fe-replete (Pollitt et al. 1989; Hathirat et al. 1992). Cognitive tests at baseline showed a significantly lower intelligence quotient in children with IDA as compared with Fe-replete children $(P<0.0008)$, but no difference between the latter and children with ID. Language scores showed significant differences between all three groups $(P<0.05)$, whereas maths scores did not differ among the groups. As in most infant studies, full correction of Fe lack following 16 weeks of Fe therapy showed no beneficial effect on educational achievement tests.

A recent study of considerable interest was performed in adolescent girls aged 13-18 years (mean $16 \cdot 2$ years) living in the USA and attending either private or public high schools (Bruner et al. 1996). Over 700 girls were screened which resulted in the identification of ninety-eight nonanaemic girls with ID as defined by a serum ferritin $<12 \mu \mathrm{g} / \mathrm{l}$. A large battery of cognitive function tests were performed before and after randomization to receive 8 weeks of $\mathrm{Fe}$ or placebo therapy. In the seventy-three girls who completed the trial, the mean serum ferritin in the treatment and control groups averaged 27.3 and $12.1 \mu \mathrm{g} / \mathrm{l}$ respectively. No differences were observed between the two groups in three independent measures of attention, whereas a significantly lower score in the control group was observed on one component of a verbal learning test $(P<0.02)$. These results disagree with a previous study in young men and women in which no association was observed between serum ferritin values and psychological functioning (Fordy \& Benton, 1994). Nevertheless, the Bruner et al. (1996) report is one of the few studies indicating a possible functional deficit in individuals with mild non-anaemic ID.

\section{Adverse perinatal outcome in pregnancy}

The highest prevalence of IDA occurs in woman during pregnancy because of the heightened $\mathrm{Fe}$ requirements associated with gestation. It is remarkable that despite decades of investigation, the adverse effects of maternal IDA or ID remain highly controversial (Allen, 1997). The prevailing concern is that significant anaemia in the mother predisposes to low birth weight and prematurity. However, the fact that the relationship between low birth weight and maternal haemoglobin concentration is U-shaped confuses the issue, because little is known about the underlying causes at either end of the extremes in haemoglobin levels (Garn et al. 1981; Klebanoff et al. 1991; Lu et al. 1991). An important recent study performed in a lowincome predominantly-black population in the USA demonstrated that IDA was associated with a 3-fold increase in preterm delivery and low birth weight (Scholl et al. 1992). The impact of this report would be far greater if it were possible to demonstrate a positive effect on birth weight with Fe supplementation. However, studies in industrialized countries have failed to demonstrate a higher birth weight with Fe supplementation (Doyle et al. 1990; Hemminki \& Merilainen, 1995), except perhaps when there is a high prevalence of IDA during pregnancy (Hemminki \& Starfield, 1978). There is a wealth of studies that demonstrate improved haematological variables with Fe supplementation during pregnancy, but it is the evidence for any benefit of this improvement which is lacking. Uncertainty about the liabilities associated with moderate IDA during pregnancy have resulted in a wide range of recommendations about the need for $\mathrm{Fe}$ supplementation. One advisory committee recently concluded that existing data is not sufficient to justify any Fe supplements during pregnancy (US Preventive Services Task Force, 1993). No one argues against the need for further research on this important issue. 


\section{Diminished work capacity}

Dramatic evidence that tissue deficiency of $\mathrm{Fe}$ is associated with a significant defect in endurance work activity, as measured by running ability in small laboratory animals, was published by Finch et al. (1976). In this and subsequent studies evidence was obtained for a defect in the oxidative production of cellular energy in skeletal muscle (Davies et al. 1984). The Finch et al. (1976) publication fostered several investigations in human subjects which indicated a parallel defect in endurance performance. Work productivity of latex tappers and weeders working on a rubber plantation in Indonesia was dramatically enhanced by $\mathrm{Fe}$ supplementation (Basta et al. 1979), and a similar benefit of $\mathrm{Fe}$ administration was observed in tea pickers living in Sri Lanka (Edgerton et al. 1979). These findings have been a driving force in efforts to reduce the prevalence of Fe lack in the developing world. In one report, it was estimated that a $15 \%$ increase in work productivity can be realized for every $10 \%$ increase in haemoglobin concentration (Levin, 1986). The nagging question in these and subsequent studies is whether the defect in work performance is due to anaemia per se, and thus applicable to all types of anaemia, or whether it reflects a defect in muscle function that is specific for Fe lack. There are numerous published studies and several reviews concerning the possible effects of IDA or ID on athletic training and physical performance (Cook, 1994; Ekblom, 1996). As with other liabilities of Fe lack, there is no convincing evidence that $\mathrm{Fe}$ supplementation in the absence of anaemia is of benefit.

\section{Laboratory assessment of iron status}

The assessment of Fe status in human subjects can only be made by using specific laboratory measurements. This technology is constantly evolving, and no single method or combination of methods is suitable for all purposes. The optimal laboratory approach depends on the anticipated severity of the Fe lack, the age and sex of the target population, the potential for associated disease, the feasibility of venous sampling, and the available economic and laboratory resources, to mention only some of the variables. The preferred methods are listed in Table 1 in approximate order of increasing severity of the Fe lack which they reflect.

\section{Body iron stores}

It is convenient when discussing the assessment of Fe status to consider body $\mathrm{Fe}$ as residing in two main compartments

Table 1. Laboratory measurements of iron status*

\section{Serum ferritin \\ 2. Transferrin saturation \\ 3. Erythrocyte protoporphyrin \\ 4. Mean corpuscular volume \\ 5. Serum transferrin receptor \\ 6. Haemoglobin or packed cell volume}

\footnotetext{
* Preferred methods in approximate order of increasing severity of the Fe lack they reflect.
}

of storage and functional Fe. The only practical laboratory method for evaluating the size of the body Fe store in epidemiological studies is the serum ferritin determination that was introduced in 1972 (Addison et al. 1972). Early experience with this key $\mathrm{Fe}$ variable has been extensively reviewed (Worwood, 1982; Finch et al. 1986). More cumbersome methods such as quantitative phlebotomy, or more invasive methods such as bone-marrow examination for stainable $\mathrm{Fe}$ have been used to validate the serum ferritin as a simple quantitative measure of $\mathrm{Fe}$ stores in otherwise healthy subjects. The majority of laboratory methods in current use are ELISA which requires only a few microlitres of serum or plasma. The stated normal range is controversial, but values of $15-300 \mu \mathrm{g} / \mathrm{l}$ serum or plasma are typically used. In healthy subjects, $1 \mu \mathrm{g}$ ferritin/l corresponds to approximately $10 \mathrm{mg}$ storage $\mathrm{Fe}$.

The overriding importance of the serum ferritin is that a low value in an anaemic individual identifies IDA unequivocally. Similarly, a high serum ferritin value above $100-150 \mu \mathrm{g} / \mathrm{l}$ is useful for excluding IDA as the cause of anaemia. Unfortunately, intermediate values between 15 and $100 \mu \mathrm{g} / \mathrm{l}$ do not necessarily exclude IDA, because a large variety of disorders elevate the serum ferritin independently of $\mathrm{Fe}$ status and result in falsely normal values in individuals with a deficiency of Fe. As an acutephase reactant, the serum ferritin is elevated by acute and chronic infections, inflammatory diseases, malignancies and liver disorders. Even alcohol consumption has been shown to affect the serum ferritin concentration in epidemiological studies (Leggett et al. 1990). Thus, the utility of the serum ferritin is enhanced if some or all these disorders can be excluded by clinical examination or other laboratory tests such as the erythrocyte sedimentation rate or C-reactive protein.

\section{Iron-deficient erythropoiesis}

The term Fe-deficient erythropoiesis has long been used in the clinical literature to refer to laboratory evidence of a sustained reduction in plasma Fe supply to developing erythrocytes. The oldest laboratory indices in current use for identifying $\mathrm{Fe}$-deficient erythropoiesis are the plasma $\mathrm{Fe}$ transport variables, serum $\mathrm{Fe}$, total Fe-binding capacity and transferrin saturation. An isolated serum Fe determination is not very useful because of the pronounced diurnal fluctuations. The total Fe-binding capacity increases with ID, but has low specificity and is at least as good an index of protein status as of $\mathrm{Fe}$ lack. The calculation of the transferrin saturation (serum Fe/total Fe-binding capacity) partly compensates for the limitations of individual measurements, but does not overcome the fundamental problem that plasma Fe transport is affected by a wide range of disorders. These transport measurements are gradually being replaced in nutritional surveys because of the large sample volume required, cumbersome laboratory technology and, most importantly, their low sensitivity and specificity for ID. Their greatest value is in limiting the diagnostic possibilities in an anaemic individual to IDA or the anaemia of chronic disease (as discussed on p. 492). It should be noted that the transferrin saturation remains the most effective method of screening for hereditary haemochromatosis. 
Measurements of erythrocyte protoporphyrin have been used for more than two decades to detect an undersupply of $\mathrm{Fe}$ to developing erythrocytes. $\mathrm{Zn}$ replaces the excess or free protoporphyrin IX which accumulates in the Fe-deprived erythrocyte, and can be measured with a portable electronic device called a haematofluorometer. Only a few microlitres of whole blood are required for the test, and minimal technical expertise is needed to obtain consistent results. A problem unique to the erythrocyte protoporphyrin is that, in addition to Fe-deficient erythropoiesis, it is also highly sensitive to environmental $\mathrm{Pb}$ exposure and varies inversely with blood $\mathrm{Pb}$ levels. The normal range for the erythrocyte protoporphyrin used in national health surveys in the USA required revision when the level declined following the legislated requirement for using $\mathrm{Pb}$-free petrol (Looker et al. 1997).

A haematological method that has been extensively used to detect Fe-deprived erythrocytes is the mean corpuscular volume, which indicates the average size of circulating erythrocytes. Reliable measurements of mean corpuscular volume require automated electronic cell-counting instruments and a fresh sample of whole blood. The mean corpuscular volume is still used by many clinicians to identify $\mathrm{Fe}$ deficient erythropoiesis in anaemic patients, a value below 80-83 fl defining microcytosis. As with most Fe-related measurements, the major limitation of the mean corpuscular volume is low sensitivity. In addition to IDA and anaemia secondary to inflammation, the mean corpuscular volume is sharply reduced in thalassaemia. If IDA is established by other laboratory criteria such as a low serum ferritin, the mean corpuscular volume is a useful guide to the severity and duration of IDA.

\section{Serum transferrin receptor}

The newest addition to the laboratory assessment of Fedeficient erythropoiesis is the serum transferrin receptor. This laboratory variable evolved from studies demonstrating that the uptake of transferrin-Fe by body cells is accomplished by means of a transmembrane receptor having a molecular mass of $190000 \mathrm{Da}$. Following the initial report that minute amounts of this well-characterized protein could be detected in the serum of human subjects (Kohgo et al. 1986), a wealth of experience has accumulated on the use of this new laboratory variable. It has been shown that the serum transferrin receptor consists of a soluble fragment of intact receptor containing most of the large extracellular domain (Shih et al. 1990). The serum transferrin receptor concentration is proportional to the total body mass of receptor, approximately $80 \%$ of which is derived from the erythroid marrow. There are only two conditions that are associated with an elevation in the serum transferrin receptor: enhanced erythrocyte production and tissue deficiency of Fe. Phlebotomy studies in normal subjects have demonstrated that following depletion of body $\mathrm{Fe}$ reserves, an elevated serum transferrin receptor is the first laboratory sign of ID and that the rise continues in direct proportion to the severity of the deficiency (Skikne et al. 1990).

The methodology and applications of the serum transferrin receptor have been reviewed in detail (Beguin, 1992;
Cook et al. 1993, 1996; Baynes et al. 1994). The majority of laboratory methods used to measure the serum transferrin receptor have been ELISA. Only a few microlitres of plasma or serum is required, and whole-blood spots dried on filter paper can also be used because of the negligible contribution from haemolysed erythrocytes (Cook et al. 1998). The wider application of serum-transferrin-receptor assays has been limited by the difficulty in purifying the receptor from human placenta, but several commercial assays are now available. Their relatively high cost at present reflects developmental expenses, but the cost should approach that of serum ferritin measurements as demand and availability increases. Unfortunately, there is a wide variation in reported values at present, reflecting differences in immunological reagents and the materials used for standardization. This variation has created an urgent need for international standardization of methods and standards.

\section{Anaemia}

The advanced stage of Fe lack is associated with anaemia. Measurement of the packed cell volume or haemoglobin concentration has been used to identify lack of $\mathrm{Fe}$ in nutritional surveys throughout most of the present century. The haemoglobin determination is in wider use than the packed cell volume at the present time because of the availability of a hand-held battery-operated instrument called a Hemocue (Hemocue Inc., Mission Viejo, CA, USA), which gives immediate and highly-accurate results in the field. The main limitation of the haemoglobin and packed cell volume is that they only identify anaemia which has hundreds of causes and therefore, cannot, be used in isolation as a indication of $\mathrm{Fe}$ status.

\section{Anaemia of chronic disease}

In an otherwise-healthy population, lack of $\mathrm{Fe}$ is the usual cause of Fe-deficient erythropoiesis. However, in a clinical setting and in many developing countries anaemia due to various inflammatory or infectious disorders referred to collectively as the anaemia of chronic disease (ACD) is a common cause of Fe-deficient erythropoiesis. The characteristic fall in transferrin saturation in the ACD results from a block in Fe release from macrophages where the Fe from senescent erythrocytes is recovered and returned to plasma transferrin. Recent studies suggest that a unifying feature of the ACD is the secretion of various cytokines from macrophages, particularly interleukin 1 and tumour necrosis factor (Lipschitz, 1990; Krantz, 1994).

Collectively, IDA and ACD account for most of the anaemia seen in clinical practice. In one study of 259 anaemic patients over 65 years of age in whom haematological investigations, including a bone-marrow examination, were performed $36 \%$ had IDA and $44 \%$ the ACD (Guyatt et al. 1990). Little is known about the prevalence of ACD in nutritional surveys because of the need for a bonemarrow examination to distinguish it from IDA, but it is undoubtedly high in many developing countries (Fleming, 1982; Isah et al. 1985). The importance of these inflammatory disorders in nutritional surveys is the confusion they create in the laboratory diagnosis of ID and IDA. 


\section{Definition of optimal body iron}

One way of regarding optimal body $\mathrm{Fe}$ is to consider the extent of Fe replenishment that is desirable in an individual with advanced IDA (Fig. 1). The two major options for defining optimal $\mathrm{Fe}$ nutrition are the correction of more severe IDA (level I) or the correction of milder ID (level II). Both options require consideration of the best laboratory methods to define IDA and ID.

\section{Correction of iron-deficiency anaemia}

Justification for defining optimal $\mathrm{Fe}$ nutrition as the correction of IDA is based on the paucity of published evidence that $\mathrm{Fe}$ lack in the absence of anaemia is associated with any functional liabilities. It can be argued, therefore, that optimal $\mathrm{Fe}$ nutrition should be defined simply as a normal haemoglobin concentration. This is the approach used by most clinicians because of their assumption that milder non-anaemic ID is of little or no clinical consequence. Relying only on the haemoglobin concentration is a reasonable approach when screening for Fe lack in segments of the population with a high prevalence of IDA such as infants and pregnant women who are otherwise in good health. However, the haemoglobin has low sensitivity due to the large overlap in values between normal and anaemic populations (Cook et al. 1971) and low specificity due to the many causes of anaemia not due to Fe lack such as malaria, thalassaemia, human immunodeficiency virus infection and the ACD. When there is the possibility of encountering these disorders in prevalence surveys it is important to include additional laboratory indices of IDA.

Any or all the laboratory measurements listed in Table 1 have been used to improve the specificity of haemoglobin determinations for detecting IDA. The importance of performing these additional measurements depends on the anticipated prevalence of other causes of anaemia in the sampled population, especially the ACD because the transferrin saturation, erythrocyte protoporphyrin, and mean corpuscular volume all fail to distinguish between IDA and

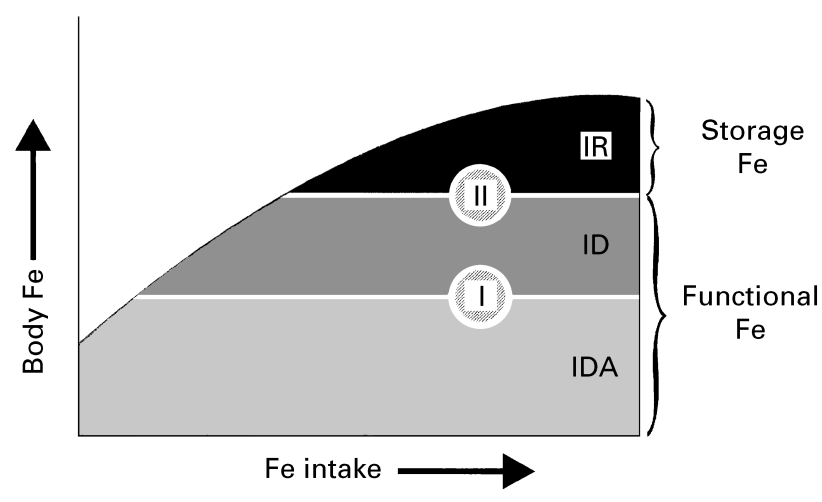

Fig. 1. Definition of optimal iron nutrition in relation to the progressive repair of advanced iron lack with oral iron administration. Body iron is divided into two main compartments of storage and functional iron. Level I corresponds to the correction of iron-deficiency anaemia (IDA) and level II to the correction of iron deficiency without anaemia (ID). Optimal iron nutrition should include a small iron reserve (IR).
ACD. The most valuable single determination to characterize the nature of anaemia is the serum ferritin because a low value identifies IDA unequivocally. The limitation of the serum ferritin is that the proportion of anaemic subjects with a serum ferritin value below the widely-accepted cut-off of $12 \mu \mathrm{g} / \mathrm{l}$ is often low. Higher cut-off levels are sometimes used, but these criteria are usually defined empirically rather than by bone-marrow examination or the response to $\mathrm{Fe}$ administration.

Another approach to enhancing the specificity of haemoglobin determinations for IDA is to use multiple laboratory criteria and require that two or more criteria be abnormal. The rationale is based on evidence that the prevalence of anaemia increases progressively with the number of abnormal indices of IDA (Cook et al. 1976). In national nutritional surveys in the USA models using various combinations of the transferrin saturation, erythrocyte protoporphyrin, serum ferritin, and mean corpuscular volume have been used. In the most recent survey conducted from 1988 to 1994, IDA was defined as a low haemoglobin concentration and at least two of three abnormalities in the serum ferritin, erythrocyte protoporphyrin, and transferrin saturation (Looker et al. 1997). It should be noted that the combination of a low transferrin saturation and high erythrocyte protoporphyrin in an anaemic individual does not distinguish between IDA and ACD.

The inclusion of the serum transferrin receptor as a laboratory criterion of IDA is very useful, because the serum transferrin receptor remains normal in the ACD but is elevated with IDA (Ferguson et al. 1992). The ability of the serum transferrin receptor to distinguish ACD from IDA, even in the presence of chronic infection or inflammation, was demonstrated convincingly in a recent study in 129 anaemic patients who underwent bone-marrow examination to determine their Fe status (Punnonen et al. 1997). The patients were divided into three groups according to the presence or absence of marrow $\mathrm{Fe}$ and clinical or laboratory evidence of a chronic inflammatory illness. There were forty-eight patients with IDA, sixty-four with ACD and seventeen patients with both ACD and IDA, referred to in the publication as the 'COMBI' group. The serum transferrin receptor performed better than the serum ferritin in identifying IDA, but the optimal approach proved to be the combined use of the serum ferritin and serum transferrin receptor by calculating serum transferrin receptor: serum ferritin. This approach permitted complete separation between IDA and ACD and, with the exception of a single patient, complete separation in patients with chronic infection between those who did and did not have marrow Fe, i.e, between ACD and 'COMBI' (ACD with IDA). The ability to detect IDA even in the presence of infection represents a major advance in the population assessment of Fe status, and argues strongly for the use of three laboratory variables in field studies of anaemia prevalence (haemoglobin, serum ferritin and serum transferrin receptor).

\section{Correction of iron deficiency}

Despite the difficulty in demonstrating significant liabilities of Fe lack in the absence of overt anaemia, it is difficult to 
regard body $\mathrm{Fe}$ status as optimal when there is a chronic deficiency in the supply of Fe to tissues (Fe-deficient erythropoiesis). In this context, Fe nutrition could be regarded as adequate when IDA is corrected, but optimal when ID is corrected.

Many investigators use the same criteria to define ID as IDA, with the exception that the haemoglobin concentration is normal in ID. If only a single laboratory variable is used to identify ID the serum ferritin is a reasonable choice, because a normal value indicates $\mathrm{Fe}$ reserves and consequently excludes ID if a false elevation due to liver disease or inflammation can be excluded. The serum ferritin alone was used effectively to determine the efficacy of $\mathrm{Fe}$ fortification in Venezuelan children (Layrisse et al. 1996). However, most investigators use more than one measure of tissue $\mathrm{Fe}$ supply from the list in Table 1. In some studies the results of these measurements are reported independently without an attempt to define ID specifically. This procedure is adequate when reporting the results of an isolated investigation, but it does not permit adequate comparisons between studies, and does not define prevalence in epidemiological work. For the latter purpose, combinations of multiple criteria are often employed, as described previously for IDA. Some recent examples include the definition of ID as two or more abnormalities in the transferrin saturation, serum ferritin, and erythrocyte protoporphyrin (Looker et al. 1997), or as two or more abnormalities in the serum ferritin, erythrocyte protoporphyrin and mean corpuscular volume (Himes et al. 1997). Unfortunately, there is no consensus on the best definition of ID when based on multiple criteria.

The incorporation of the serum transferrin receptor in the definition of ID makes good physiological and biochemical sense, because upregulation of transferrin-receptor synthesis is the initial and fundamental intracellular response to a reduction in cellular Fe supply. Recent investigations have demonstrated the sensitivity of the serum transferrin receptor as an index of marginal ID (Beguin et al. 1997; Zhu $\&$ Haas, 1998). The serum transferrin receptor becomes an even more effective variable when used in tandem with the serum ferritin, which measures the quantity of storage Fe, while the serum transferrin receptor measures the degree of tissue deficiency of Fe. The value in using the combination of the serum ferritin and serum transferrin receptor was demonstrated in controlled phlebotomy studies that gave a precise measure of body $\mathrm{Fe}$ at each point of evolving Fe lack (Skikne et al. 1990). It was shown that serum transferrin receptor : ferritin was directly proportional to body Fe over a wide spectrum of $\mathrm{Fe}$ status ranging from replete $\mathrm{Fe}$ stores to overt IDA. This ratio provides a quantitative estimate of body $\mathrm{Fe}$ in each sampled individual, and allows the Fe status of a population to be portrayed as a frequency distribution rather than as the proportion of individuals above or below an arbitrary cut-off level for a particular laboratory measurement.

\section{Conclusions}

Optimal Fe nutrition is best defined as the normality of key laboratory indices of body $\mathrm{Fe}$ status. The most effective combination of laboratory criteria is a normal haemoglobin concentration which eliminates IDA, a normal serum transferrin receptor which establishes adequate tissue $\mathrm{Fe}$ supply, and a normal serum ferritin which reflects the presence of storage Fe.

\section{References}

Addison GM, Beamish MR, Hales CN, Hodgkins M, Jacobs A \& Llewellin P (1972) An immunoradiometric assay for ferritin in the serum of normal subjects and patients with iron deficiency and iron overload. Journal of Clinical Pathology 25, 326-329.

Allen LH (1997) Pregnancy and iron deficiency: unresolved issues. Nutrition Reviews 55, 91-101.

Basta SS, Soekirman MS, Karyadi D \& Scrimshaw NS (1979) Iron deficiency anemia and the productivity of adult males in Indonesia. American Journal of Clinical Nutrition 32, 916-925.

Baynes RD, Skikne BS \& Cook JD (1994) Circulating transferrin receptors and assessment of iron status. Journal of Nutritional Biochemistry 5, 322-330.

Beguin Y (1992) The soluble transferrin receptor: Biological aspects and clinical usefulness as quantitative measure of erythropoiesis. Haematologica 77, 1-10.

Beguin Y, Grek V, Weber G, Sautois B, Paquot N, Pereira M, Scheen A, Lefebvre P \& Fillet G (1997) Acute functional iron deficiency in obese subjects during a very-low-energy all-protein diet. American Journal of Clinical Nutrition 66, 75-79.

Bruner AB, Joffe A, Duggan AK, Casella JF \& Brandt J (1996) Randomised study of cognitive effects of iron supplementation in non-anaemic iron-deficient adolescent girls. Lancet 348, 992996.

Chwang LC, Soemantri AG \& Pollitt E (1988) Iron supplementation and physical growth of rural Indonesian children. American Journal of Clinical Nutrition 47, 496-501.

Cook JD (1994) The effect of endurance training on iron metabolism. Seminars in Hematology 31, 146-154.

Cook JD, Alvarado J, Gutniskey A, Jamra M, Labardini J, Layrisse M, Linares J, Loria A, Maspes V, Restrepo A, Reynafarje C, Sanchez-Medal L, Velez H \& Viteri F (1971) Nutritional deficiency and anemia in Latin America: a collaborative study. Blood 38, 591-603.

Cook JD, Finch CA \& Smith NJ (1976) Evaluation of the iron status of a population. Blood 48, 449-455.

Cook JD, Flowers CH \& Skikne BS (1998) An assessment of dried blood spot technology for identifying iron deficiency. Blood $\mathbf{9 2}$, 1807-1813.

Cook JD, Skikne BS \& Baynes RD (1993) Serum transferrin receptor. Annual Review of Medicine 44, 63-74.

Cook JD, Skikne B \& Baynes R (1996) The use of the serum transferrin receptor for the assessment of iron status. In Iron Nutrition in Health and Disease, pp. 49-58 [L Hallberg and NG Asp, editors]. London: John Libbey \& Company Ltd.

Davies KJA, Donovan CM, Refino CJ, Brooks GA, Packer L \& Dallman PR (1984) Distinguishing effects of anemia and muscle iron deficiency on exercise bioenergetics in the rat. American Journal of Physiology 246, E535-E543.

De Andraca I, Castillo M \& Walter T (1997) Psychomotor development and behavior in iron-deficient anemic infants. Nutrition Reviews 55, 125-132.

Doyle W, Crawford MA, Wynn AHA \& Wynn SW (1990) The association between maternal diet and birth dimensions. Journal of Nutrition in Medicine 1, 9-17.

Edgerton VR, Gardner GW, Ohira Y, Gunawardena KA \& Senewiratne B (1979) Iron-deficiency anaemia and its effect on worker productivity and activity patterns. British Medical Journal 2, 1546-1549. 
Ekblom B (1996) Iron deficiency, anemia and physical performance. In Iron Nutrition in Health and Disease, pp. 195203 [L Hallberg and NG Asp, editors]. London: John Libbey \& Company Ltd.

Ferguson BJ, Skikne BS, Simpson KM, Baynes RD \& Cook JD (1992) Serum transferrin receptor distinguishes the anemia of chronic disease from iron deficiency anemia. Journal of Laboratory and Clinical Medicine 119, 385-390.

Finch CA, Bellotti V, Stray S, Lipschitz DA, Cook JD, Pippard MJ $\&$ Huebers HA (1986) Plasma ferritin determination as a diagnostic tool. Western Journal of Medicine 145, 657-663.

Finch CA, Miller LR, Inamdar AR, Person R, Seiler K \& Mackler B (1976) Iron deficiency in the rat. X Physiological and biochemical studies of muscle dysfunction. Journal of Clinical Investigation 58, 447-453.

Fleming AF (1982) Iron deficiency in the tropics. Clinics in Haematology 11, 365-388.

Fordy J \& Benton D (1994) Does low iron influence psychological functioning? Journal of Human Nutrition and Dietetics 7, 127133.

Garn SM, Ridella SA, Tetzold AS \& Falkner F (1981) Maternal haematological levels and pregnancy outcomes. Seminars in Perinatology 5, 155-162.

Guyatt GH, Patterson C, Ali M, Singer J, Levine M, Turpie I \& Meyer R (1990) Diagnosis of iron-deficiency anemia in the elderly. American Journal of Medicine 88, 205-209.

Hathirat P, Valyasevi A, Kotchabhakdi NJ, Rojroongwasinkul N \& Pollitt E (1992) Effects of an iron supplementation trial on the Fe status of Thai schoolchildren. British Journal of Nutrition $\mathbf{6 8}$, $245-252$.

Hemminki E \& Merilainen J (1995) Long-term follow-up of mothers and their infants in a randomized trial on iron prophylaxis during pregnancy. American Journal of Obstetrics and Gynecology 173, 205-209.

Hemminki E \& Starfield B (1978) Routine administration of iron and vitamins during pregnancy: review of controlled clinical trials. British Journal of Obstetrics and Gynaecology 85, 404-410.

Himes JH, Walker SP, Williams S, Bennett F \& GranthamMcGregor SM (1997) A method to estimate prevalence of iron deficiency and iron deficiency anemia in adolescent Jamaican girls. American Journal of Clinical Nutrition 65, 831-836.

Idjradinata P \& Pollitt E (1993) Reversal of developmental delays in iron-deficient anaemic infants treated with iron. Lancet 341, $1-4$.

Isah HS, Fleming AF, Ujah IA \& Ekwempu CC (1985) Anaemia and iron status of pregnant and non-pregnant women in the guinea savanna of Nigeria. Annals of Tropical Medicine and Parasitology 79, 485-493.

Klebanoff MA, Shiono PH, Selby JV, Trachtenberg AI \& Graubard BI (1991) Anemia and spontaneous preterm birth. American Journal of Obstetrics and Gynecology 164, 59-63.

Kohgo Y, Nishisato T, Kondo H, Tsushima N, Niitsu Y \& Urushizaki I (1986) Circulating transferrin receptor in human serum. British Journal of Haematology 64, 277-281.

Krantz SB (1994) Pathogenesis and treatment of the anemia of chronic disease. American Journal of the Medical Sciences 307, 353-359.
Layrisse M, Chaves JF, Mendez-Castellano, Bosch V, Tropper E, Bastardo B \& Gonzalez E (1996) Early response to the effect of iron fortification in the Venezuelan population. American Journal of Clinical Nutrition 64, 903-907.

Leggett BA, Brown NN, Bryant SJ, Duplock L, Powell LW \& Halliday JW (1990) Factors affecting the concentrations of ferritin in serum in a healthy Australian population. Clinical Chemistry 36, 1350-1355.

Levin HM (1986) A benefit-cost analysis of nutritional programs for anaemia reduction. Research Observations 1, 219-245.

Lipschitz DA (1990) The anemia of chronic disease. Journal of the American Geriatric Society 38, 1258-1264.

Looker AC, Dallman PR, Carroll MD, Gunter EW \& Johnson CL (1997) Prevalence of iron deficiency in the United States. Journal of the American Medical Association 277, 973-976.

Lozoff B, Brittenham GM, Wolf AW, McClish DK, Kuhnert PM, Jimenez E, Jimenez R, Mora LA, Gomez I \& Krauskoph D (1987) Iron deficiency anemia and iron therapy: Effects on infant developmental test performance. Pediatrics 79, 981-995.

Lozoff B, Wolf AW \& Jimenez E (1996) Iron-deficiency anemia and infant development: effects of extended oral iron therapy. Journal of Pediatrics 129, 382-389.

Lu ZM, Goldenberg R, Cliver S, Cutter G \& Blankson M (1991) The relationship between maternal hematocrit and pregnancy outcome. Obstetrics and Gynecology 77, 190-194.

Pollitt E (1997) Iron deficiency and educational deficiency. Nutrition Reviews 55, 133-141.

Pollitt E, Hathirat P, Kotchabhakdi NJ, Missell L \& Valyasevi A (1989) Iron deficiency and educational achievement in Thailand. American Journal of Clinical Nutrition 50, 687-697.

Punnonen K, Irjala K \& Rajamaki A (1997) Serum transferrin receptor and its ratio to serum ferritin in the diagnosis of iron deficiency. Blood 89, 1052-1057.

Scholl TO, Hediger ML, Fischer RL \& Shearer JW (1992) Anemia vs iron deficiency: increased risk of preterm delivery in a prospective study. American Journal of Clinical Nutrition 55, 985-988.

Shih YJ, Baynes RD, Hudson BG, Flowers CH, Skikne BS \& Cook JD (1990) Serum transferrin receptor is a truncated form of tissue receptor. Journal of Biological Chemistry $\mathbf{2 6 5}$, 19077-19081.

Skikne BS, Flowers CH \& Cook JD (1990) Serum transferrin receptor: A quantitative measure of tissue iron deficiency. Blood 75, 1870-1876.

Soemantri AG, Pollitt E \& Kim I (1985) Iron deficiency anemia and educational achievement. American Journal of Clinical Nutrition 42, 1221-1228.

US Preventive Services Task Force (1993) Routine iron supplementation during pregnancy. Journal of the American Medical Association 270, 2846-2854.

Walter T, De Andraca I, Chadud P \& Perales CG (1989) Iron deficiency anemia: Adverse effects on infant psychomotor development. Pediatrics 84, 7-17.

Worwood M (1982) Ferritin in human tissues and serum. Clinics in Haematology 11, 275-307.

Zhu YI \& Haas JD (1998) Response of serum transferrin receptor to iron supplementation in iron-depleted, nonanemic women. American Journal of Clinical Nutrition 67, 271-275. 
https://doi.org/10.1017/S0029665199000634 Published online by Cambridge University Press 